\section{Dr. Radic, et al reply}

\section{To the Editor:}

We thank Conway and colleagues for their interest in our article ${ }^{1}$. The major thrust of our report was not to debate whether biological therapy is good or bad, beneficial or not, for autoimmune sensorineural hearing loss (AISNHL) treatment. Our purpose was to present a very interesting case report of successful use of adalimumab for treating rheumatoid arthritis (RA) with AISNHL. The classic description of AISNHL by McCabe includes responsiveness to immunosuppression ${ }^{2}$. Use of other immunomodulators to maintain improvements in steroid-responsive patients is advocated to reduce the side effects of longterm corticosteroids. The most researched nonsteroidal agents in animal models of AISNHL are inhibitors of TNF- $\alpha$, mostly etanercept ${ }^{3,4,5}$. Animal models with keyhole limpet hemocyanin-induced labyrinthitis treated with etanercept found decreased cochlear inflammation with reduction of hearing loss. Nevertheless, human clinical studies have given contradictory results on AISNHL treatment with etanercept, mostly negative $e^{6,7}$. One pilot study described the efficacy of intratympanic application of infliximab for treatment of AISNHL by allowing steroid taper and facilitating hearing improvement ${ }^{8}$.

In contrast to our results, Conway, et al described 2 cases of AISNHL related to adalimumab therapy. It is very hard to distinguish whether this is a side effect of adalimumab therapy or AISNHL in association with autoimmune disease such as RA. The pathophysiology of AISNHL is largely unknown and possible treatment with nonsteroidal medications has yet to be identified. We agree that inhibitors of TNF- $\alpha$ should be used with great caution for AISNHL treatment. Appropriate treatment of AISNHL may provide reversal of sensorineural hearing loss and may best be served by exploring new treatment modalities, focusing on intratympanic delivery.

MISLAV RADIC, MD, Department of Rheumatology, University Hospital Split, Split; JADRANKA MOROVIC VERGLES, MD, PhD, Professor, Department of Rheumatology and Clinical Immunology; JELENA KOVACIC, MD, Department of Otorhinolaryngology; LEA SALAMON, MD, Department of Rheumatology and Clinical Immunology, Dubrava University Hospital, Zagreb, Croatia. Address correspondence to Dr. M. Radic, University Hospital Split, Department of Rheumatology, Soltanska 1, Split 21000, Croatia. E-mail: mislavradic@gmail.com

\section{REFERENCES}

1. Morovic Vergles J, Radic M, Kovacic J, Salamon L. Successful use of adalimumab for treating rheumatoid arthritis with autoimmune sensorineural hearing loss: two birds with one stone [letter]. J Rheumatol 2010;37:1080-1.

2. McCabe BF. Autoimmune sensorineural hearing loss. Ann Otol Rhinol Laryngol 1979;88:585-9.

3. Satoh H, Firestein GS, Billings PB, Harris JP, Keithley EM. Tumor necrosis factor- $\alpha$, an initiator, and etanercept, an inhibitor of cochlear inflammation. Laryngoscop 2002;112:1627-34.

4. Peppel K, Crawford D, Beutler B. A tumor necrosis factor (TNF) receptor-IgG heavy chain chimeric protein as a bivalent antagonist of TNF activity. J Exp Med 1991;174:1483-9.

5. Satoh H, Firestein GS, Billings PB, Harris JP, Keithley EM. Proinflammatory cytokine expression in the endolymphatic sac during inner ear inflammation. J Assoc Res Otolaryngol 2003;4:139-47.

6. Cohen S, Shoup A, Weisman MH, Harris J. Etanercept treatment for autoimmune inner ear disease: results of a pilot placebo-controlled study. Otol Neurotol 2005;26:903-7.

7. Street I, Jobanputra P, Proops DW. Etanercept, a tumour necrosis factor alpha receptor antagonist, and methotrexate in acute sensorineural hearing loss. J Laryngol Otol 2006;120:1064-6.

8. Van Wijk F, Staecker H, Keithley E, Lefebvre PP. Local perfusion of the tumor necrosis factor $\alpha$ blocker infliximab to the inner ear improves autoimmune neurosensory hearing loss. Audiol Neurootol 2006;11:357-65.

J Rheumatol 2011;38:1; doi:10.3899/jrheum.100774 